anales de psicología, 2018, vol. 34, $\mathrm{n}^{\circ} 1$ (january), 146-152 http://dx.doi.org/10.6018/analesps.34.1.267381
(C) Copyright 2018: Editum. Servicio de Publicaciones de la Universidad de Murcia. Murcia (Spain) ISSN print edition: 0212-9728. ISSN web edition (http://revistas.um.es/analesps): 1695-2294

\title{
Psychometric properties and factor structure of the Satisfaction with Life Scale in an elderly Portuguese retirees students sample
}

\author{
Yolanda López-Ramos ${ }^{1}$, Esperanza Navarro-Pardo ${ }^{1 *}$, Juan José Fernández-Muñoz ${ }^{2}$, and Ricardo Filipe da Silva Pocinho ${ }^{3}$ \\ 1 Universitat de València (Spain). \\ 2 Universidad Rey Juan Carlos (Spain). \\ 3 Coimbra Health School (Escola Superior de Tecnologia da Saúde de Coimbra, ESTEC). (Portugal).
}

\begin{abstract}
Título: Propiedades psicométricas y estructura de los factores de la escala de Satisfacción con la Vida en una muestra de estudiantes mayores portugueses jubilados.

Resumen: El objetivo principal de este estudio ha sido analizar las propiedades psicométricas de la escala de Satisfacción con la Vida (SWLS) en una muestra de 363 estudiantes jubilados pertenecientes a varias universidades portuguesas. El $70 \%$ de los participantes eran mujeres frente a un $30 \%$ de hombres, con una media de edad de 67 años $(S D=7.59)$ y un rango de edad comprendido entre 48 y 90 años. Se realizó un Análisis Factorial Exploratorio con R Commander y un Análisis Factorial Confirmatorio con Amos 18.0. El modelo que obtuvo un mejor ajuste estaba compuesto por un único factor. El índice de consistencia interna de la escala en su conjunto fue de .777 . En cuanto a la validez concurrente, los análisis correlacionales mostraron una correlación negativa y significativa con la escala de soledad de UCLA y con la de depresión (GDS-15). El SWLS es una escala aplicable en futuras investigaciones sobre población mayor para medir su satisfacción con la vida. Algunas limitaciones y resultados de sus aplicaciones en otras muestras son discutidos.
\end{abstract}

Palabras clave: Satisfacción con la vida; soledad; depresión; validez y fiabilidad.

\section{Introduction}

The study of human happiness, related to research concepts such as quality of life, life satisfaction or subjective wellbeing, has been an important subject of interest for centuries. It is important to distinguish between concepts such as life quality, well-being, satisfaction with life or others related to aging such as positive aging or active aging (FernándezBallesteros, 2011). Most of the research regarding life satisfaction has been specifically framed in the construct of subjective well-being (Diener, Emmons, Larson, \& Griffin, 1985; Pavot \& Diener, 1993) which includes two broad components: affective and cognitive. The affective component of subjective well-being refers to pleasant and unpleasant affects, while the cognitive component refers to satisfaction with life (Aishvarya et al., 2014; Diener \& Lucas, 1999; Pavot \& Diener, 1993). Satisfaction with life has been defined as a subjective judgment (positive and negative assignment) that people make about their overall quality of life (Cabañero et al., 2004; Oliver, Navarro-Pardo, Meléndez, Molina, \& Tomás, 2009). According to some authors (Shin \& Johnson, 1978), satisfaction with life is a judgment process whereby an individual assesses his quality of life based on a unique set of criteria. Different scales have been developed to measure life satisfaction. In particular, the Satisfaction with Life Scale

* Correspondence address [Dirección para correspondencia]:

Esperanza Navarro-Pardo; Department of Developmental and Educational Psychology. Universitat de València. Av. Blasco Ibáñez, 21. 46010 Valencia (Spain). E-mail: esperanza.navarro@uv.es
Abstract: The main purpose of this study is to analyse the psychometric properties of the Satisfaction with Life Scale (SWLS) in a 363 retirees students sample from several Portuguese universities. The $70 \%$ were female (253) and $30 \%$ were male (110) with an average age of 67 years (SD = 7.59) and a range from 48 to 90 years. $\mathrm{R}$ Commander was used for Exploratory Factor Analysis (EFA) and Amos 18.0 module for Confirmatory Factor Analysis (CFA). One factor solution was the best-fitting model. The internal consistency of the SWLS was .777. Correlational analysis showed negative relationships with loneliness (UCLA Scale) and symptoms of depression (GDS-15), supporting concurrent validity. The SWLS can be used with confidence in future research among elderly students to measure their life satisfaction. Some limitations of the results and its applications in other samples are discussed.

Keywords: Satisfaction with life; loneliness; depression; validity and reliability.

(SWLS) was based on the idea that one must ask subjects to make an overall judgment of their life in order to measure the concept of life satisfaction.

It is widely known that the number of elderly people is increasing year by year, a phenomenon which impacts on the increasing public interest and volume of research regarding the factors which have the greatest influence on the life satisfaction of the elderly. Some authors (Fletcher, Dickinson, \& Philp, 1992) have suggested that quality of life in old age is determined by the complex interaction of the characteristics of individuals and their environment. Other studies (Garrido, Méndez, \& Abellán, 2013) have shown that quality of life in adults depends on more than good health; it also involves factors such as perceived social contact. Further, the variables which determine quality of life for the elderly could be as diverse as family relationships, social contacts, general health, functional status, the home and financial situation (Meléndez, Tomás y Navarro-Pardo, 2011; Molina, Meléndez y Navarro-Pardo, 2008). Particularly notable was the finding that perception of quality of life varied depending on age group which would lead to differential study of this age group.

Another quality of life study carried out in Great Britain (Zahava \& Bowling, 2004) gathered data from 999 people over 65 years old and found that quality of life assessments included both relational factors (fundamentally social) and material factors, principally health and safety, having good social relationships, help and support; living in a home and neighbourhood feels safe, have access to local facilities and 
services including transport; engaging in hobbies and leisure activities (alone) as well as maintaining social activities and maintaining a role in society; having a positive psychological outlook and acceptance of circumstances which cannot be changed; and having enough money to meet basic needs, participate in society, enjoy life and maintain one's independence and control over life.

The most influential discrepancy predictors of respondents' overall life assessments were those between what respondents have versus what they want, followed by what they have versus what others of the same age and sex have, and then by what they have versus the best they ever had in the past (Nunes, 2000).

In particular, several researchers (Börsch-Supan \& Jürges, 2005; Fernández, Alcover de la Hera, \& Crego, 2012; Kim \& Feldman, 2000) have identified a number of criteria associated with elderly and retired people and reported their influence on satisfaction with life in the elderly during the post work period; for instance, financial situation, levels of socialization, social support, personality traits, flexibility, the use of coping strategies or participation in educational programmes as a preventive measure (Fernández et al., 2012; NavarroPardo et al., 2015). These factors have a strong influence on subjective well-being, and this is particularly so among the elderly because they have to adjust their activities, thoughts and emotions to obtain high levels of satisfaction during this period (post-working life).

With regard to well-being in old age, other authors suggest that to achieve positive functioning at advanced ages attention must be given to factors such as personal growth, goals and objectives, and the quality of personal relationships including, in addition, self-development goals and an interest in the well-being of others, which are also associated with feelings of well-being in old age (Lapierre, Bouffard, \& Bastin, 1997; Tomás, Meléndez y Navarro-Pardo, 2008). Some researchers propose that a brief psychological intervention could help to protect subjective well-being (Armitage, 2016).

However, to measure subjective well-being and life satisfaction, we must also study loneliness, because this is a highly-important phenomenon in mental health and an important negative associated factor which is most prevalent in this age group. In 1973, Weiss (1973) suggested its multidimensional nature for the first time, distinguishing between two types of loneliness: social and emotional. Social loneliness is a lack of social relationships, a feeling of not being accepted by others, isolation and boredom. The individual seeks a place in a group of people with whom he can share his interests and worries. On the other hand, emotional loneliness is a lack of close personal relationships, those which are particularly significant and provide the individual with a solid foundation for emotional development (Bowlby, 1982). Emotional loneliness is associated with feelings of emptiness and a yearning for someone special to share life with.

To enable better analysis of loneliness, different scales attempt to quantify it within a population. One of the most well-known is the UCLA (University of California Los Ange- les Loneliness Scale), which was developed by Russell, Peplau, and Cutrona (1980) to evaluate loneliness as a unidimensional state which varies in intensity (feeling lonely to a greater or lesser degree) as a consequence of the individual's lack of relationships. Later it was proved that loneliness could also be studied from a multidimensional view, composed of diverse factors, for instance, intimate loneliness, feeling isolated, feeling estranged or feeling marginalised (McWhirter, 1997). The UCLA scale has been validated in different and numerous populations. Some authors (Russell, 1980) identified certain groups at risk of suffering loneliness, such as North American university students (living away from their family for the first time), adult psychiatric patients, participants in social skills improvement groups and divorcees. Years later, other research (Exposito \& Moya, 1993) used the UCLA scale with a sample of Spanish university students and found that the people who scored high in loneliness presented low self-esteem, high levels of anxiety and depression and feelings of hostility, as well as social avoidance behaviours.

Recently, this scale was used with a sample of 4,522 elderly Singaporean people and demonstrated that loneliness is associated with higher mortality risks among the Singaporean elderly (Chan, Raman, Ma, \& Malhotra, 2015). Mental health in the older population is a major public health concern and community interventions are needed to more efficiently identify, raise awareness of, and increase care for the lonely elderly in the community.

In the latest version of the scale, the wording of the items and the answer format have been simplified to facilitate the evaluation of populations with a low level of education, as is the case with a significant proportion of elderly people (Russell, 1996). This is one of the reasons why the scale is highly applicable to our sample, as well as being an instrument which has already been validated in a Portuguese population (Pocinho, Farate, \& Dias, 2010).

Another factor related to loneliness is the socioeconomic level. In this way some authors have suggested that older people experience feelings of loneliness and dissatisfaction with life when their financial situation is poorer. The literature has shown the predictive effect of financial situation on quality of life satisfaction (De Jong Gierveld, Keating, \& Fast, 2015).

It is also important to consider the relationship between life satisfaction and depression in elderly. Depression in the elderly is a mixed picture with certain distinctive features. Psychosocial factors (financial problems, social isolation, loss of loved ones, etc.) play an important role in its etiopathogenesis, unlike in younger groups. Moreover, biological changes involved in aging, presence of cognitive deficits, coexistence of other medical problems and use of multiple medications make the elderly more likely to present symptoms of depression.

The characteristics of depression in this age group mean it is diagnosed infrequently and treated even less often (Lebowitz et al., 1998). Symptoms of depression are common 
among the elderly and it is important to be able to access a reliable and easy-to-use screening scale to facilitate their detection. In our study we have used the Geriatric Depression Scale (GDS-15) (Yesavage, Rose, Lum, \& Leirer, 1983). Another study (Pocinho, Farate, Dias, Lee, \& Yesavage, 2009) adapted the Geriatric Depression Scale (GDS) for the Portuguese population and obtained a final version with 27 items. The Cronbach's alpha was $\left(\alpha_{(27 \text { items })}=.995\right)$ and the interrater reliability $(\mathrm{Kappa}=.87)$. This conclusion was further validated by both discriminant function analysis and diagnostic value testing, which showed a sensitivity of $100 \%$, a specificity of $83 \%$, a positive predictive value of $93 \%$, and a negative predictive value of $100 \%$.

Another study of depression was carried out with a sample of 889 elderly Portuguese people and has contributed towards the validation of the Portuguese language versions of the Geriatric Depression Scale (GDS) using 15, 10 and 5 items. It was shown that all these versions of the GDS have good psychometric properties and can be used to detect symptoms of depression in the elderly (Apóstolo et al., 2014).

Cardona, Segura, Segura, and Garzón (2015) examined the association between place of residence and depression. The authors sought to determine the effects of the municipality and block of residence on the depression risk variability in the elderly in the Department of Antioquia, Colombia. A sample of 4,060 elderly people from that Department was evaluated. Demographic, social and functional characteristics were assessed to calculate raw and adjusted odds ratios and find a connection between the risk of depression, as measured by Yesavage's Geriatric Depression Scale, and context variables (municipality and block of residence) in the design of the model. The prevalence of the risk of depression was $29.5 \%$ and associations were found with ages over 75 , being female, residing in rural areas, and widowhood. Additionally, the sample presented a higher risk of anxiety, moderate functional capacity and malnutrition. The municipality and block of residence present a $10 \%$ contribution toward the total variability in the risk of depression for the elderly. These results demonstrate the importance of encouraging the elderly to participate in and join community groups.

Finally, after reviewing the main concepts related to life satisfaction, such as quality of life, subjective well-being, loneliness and depression, we will now discuss in further depth research which uses one of the most-used instruments to assess subjective well-being, the Satisfaction with Life Scale (SWLS) (Diener et al., 1985).

This scale has fulfilled the need for a multi-item scale that measures satisfaction with life as a cognitive judgment process. The items are global, leading respondents to evaluate the areas of their lives according to their own values and offering general judgment on life satisfaction. The scale has been validated in many samples and in many different languages, including Swedish students (Hultell and Gustavsson, 2008), Spanish adolescents (Atienza, Pons, Balaguer y García-Merita, 2000; Neto, 1993), pregnant and puerperium women (Cabañero et al., 2004), general population (Abdallah, 1998; Bai, Wu, Zheng, \& Ren, 2011; Gouveia et al., 2009), different Brazilian samples (Gouveia, Milfont, Fonseca, \& Coelho, 2009), a German population (Glaesmer, Grande, Braehler, \& Roth, 2011), in Hebrew (Anaby, Jarus, \& Zumbo, 2010), and psychiatric and medical outpatients and the elderly (Aishvarya et al., 2014; Michalos et al., 2007). The Social Science Citation Index shows that this scale has been used in more than 4000 studies. Several researchers have applied the SWLS scale in a Portuguese context and with an elderly sample in order to relate their perception of well-being to other variables. Von Humboldt, Leal, and Pimenta (2014) used the SWLS in a cross-sectional study with older adults from four different nationalities residing in Portugal. They found no significant differences in satisfaction with life. Also in Portuguese, a Brazilian researcher carried out a study to determine subjective well-being in older people attending intergenerational activities. The results showed that subjective well-being is significantly correlated with intergenerational activities, and the greater the participation of older peoples in these activities the higher their level of subjective well-being (Nunes, 2000).

To sum up, there are many studies which use the SWLS scale to evaluate subjective well-being in several populations. However, our view is that there are not many studies which use this scale on elderly Portuguese student samples and those which do focus mainly on active and successful elderly people. We believe it is important to use the SWLS to determine subjective well-being in this population during this new period of their lives. For these reasons the main purpose of this study is to analyse the factor structure of the SWLS and check its psychometric properties, validity and reliability, in a sample of active Portuguese elderly people.

\section{Methods}

\section{Participants}

The selected sample was composed of 363 people who participate in university programs for elderly; $70 \%$ were female (253) and 30\% were male (110). The analysis included data from several area of Portugal (north $38.3 \%$, middle area $51.8 \%$ and south $9.7 \%$ ). The average age was 67 years $(S D=$ $7.59)$, with a range from 48 to 90 years. About educational attainment, $40.8 \%$ completed basic education, $47.7 \%$ completed secondary level studies and $11.5 \%$ finished higher education; according to marital status $6.1 \%$ was single; $62.3 \%$ married; $23.9 \%$ widowed and $7.7 \%$ divorced. As for professional category, $16.5 \%$ were managers; $25.9 \%$ skilled workers; $14.9 \%$ technicians; $11.6 \%$ unskilled workers, $4.4 \%$ administrative employees and $26.7 \%$ no answers. Finally, in relation to the number of years at the senior university: $15.7 \%$ had studied for less than one year, $9.6 \%$ for a year, $22.3 \%$ for two academic years, $22 \%$ for three years, $8 \%$ for four year and $22.3 \%$ for more than five years. 


\section{Procedure}

The sampling procedure was incidental. The seniors were enrolled in educational programmes for older people offered by different Portuguese universities during an academic year (first semester, course 2015-2016). Prior to filling out the questionnaire, participants were briefed on how to complete it. The questionnaire was self-administered under the supervision of trained psychologists during one of the classes, with duration of approximately 30 minutes. Participants filled in the Satisfaction with Life Scale (SWLS), the Geriatric Depression Scale (GDS-15) and the University of California Los Angeles Loneliness Scale (UCLA-6). Permission was gained from both the University and the teacher responsible for the class. Participants were volunteers and completed the necessary informed consent documentation. The data analyses were performed using $\mathrm{R}$ commander and Amos module 18.0.

\section{Instruments}

The Satisfaction with Life Scale (SWLS) (Diener et al., 1985) was developed to measure the level of satisfaction with life. The original scale was composed of 5 items: item 1: "In most ways my life is close to my ideal"; item 2: "The conditions of my life are excellent"; item 3: "I am satisfied with my life"; item 4: "So far I have gotten the important things I want in life"; and item 5: "If I could live my life afresh, I would change almost nothing". The answer scales were composed of 7 points where $1=$ strongly disagree and $7=$ strongly agree. The internal consistency index for the general scale was $\alpha=.87$. The item-total correlations for the original SWLS were: item $1=.75$, item $2=.69$, item $3=.75$, item 4 $=.67$ and item $5=.57$. The SWLS was adapted for the Portuguese population in previous researches (Neto, Barros, \& Barros, 1990; Simões, 1992). A Portuguese version of the SWLS for Angolan people (Sancho, Galiana, Gutiérrez, Francisco, \& Tomás, 2014) was validated through confirmatory factor analysis, with a sample of 1003 Angolan elderly; the results shown that the scale had an adequate one-factor confirmatory solution, satisfactory reliability indices, and adequate criterion-related validity when assessed in the Angolan people sample.

The University of California Los Angeles Loneliness Scale (UCLA-6) (Russell, 1980) is composed of 6 items with four response options, ranging from never $=1$ and often $=4$. All questions were negatively worded or directed toward solitude, in response to which the subjects indicated how often they had feeling of loneliness. The Cronbach's alpha for the general scale was acceptable $(a=.70)$. As already mentioned, the scale was validated for the Portuguese population (Pocinho et al., 2010).

The Geriatric Depression Scale (GDS-15) (Yesavage et al., 1983) is a widely-used depression screening device specifically for the elderly. The 15 items on the short form require a yes/no answer and therefore the questionnaire is particu- larly easy to administer. Although it is a self-report measure, it can be applied by an interviewer. The scale focuses mainly on the worries of the patients and the way the elderly conceive and interpret their quality of life. It is designed to register a cognitive dimension of depression. The Cronbach's alpha for the general scale was acceptable $(\alpha=.67)$. Some researchers have contributed to the adaptation of the GDS-15 into Portuguese population (Apóstolo et al., 2014).

\section{Results}

\section{Analysis}

$\mathrm{R}$ commander program was used for exploratory factor analysis (EFA), and Amos 18.0 module for confirmatory factor analysis (CFA). Assumptions were checked to ensure the application of factor analysis, high sample size, multivariate normality, linearity and correlation between variables (Tabachnick \& Fidell, 1989). Due to the original structure of this scale, it was not necessary to apply a rotation process. The estimation method was maximum likelihood. This method of estimation is common in factor analysis and structural equation models, and assumes that the distribution of the data is multivariate normal (Brown, 2006). In order to identify the adequate number of factors, two main criteria were applied: Cattell's scree-plot (Cattell, 1966) and Horn's parallel analysis (Horn, 1965). As all Monte Carlo methods, Parallel Analysis requires an intensive computational process. In fact, some authors have indicated that one of the main drawbacks of Parallel Analysis is that it can be quite costly in terms of computation time (Montanelli \& Humphreys, 1976). By this reason we applied Parallel Analysis with FACTOR software (http://psico.fcep.urv.es/utilitats/factor/Download.html). We obtained the same number of factors between several criteria (Cattell's scree-plot and Parallel Analysis) and the best solution had one factor.

According to several authors (Lloret-Segura, FerreresTraver, Hernández-Baeza, \& Tomás-Marco, 2014) we applied to randomly split the sample in half and with the first subsample we ran an EFA. Once the EFA reveals the best number of factors to represent the data and then conduct a CFA on the second random half to confirm that this new factor structure fits the data. The adequacy of the overall fit has been confirmed using the following absolute fit indices: the chi-square statistic $\chi^{2}$ (Jöreskog, Sörbom, \& Magidson, 1979), the goodness of fit index (GFI) whose reference value is .90 for an acceptable model (Hu \& Bentler, 1990), and the root mean square residual (RMR) based directly on the residuals (when the residuals are close to 0 the value of RMR is 0 , therefore the lower the value, the better the fit) and with a reference value of .08 (Jöreskog et al., 1979). The incremental fit indices used were: the comparative fit index (CFI), the normed-fit index (NFI), also called delta 1 , and the incremental fit index (IFI). In all three of these cases the range of values is between 0 and 1 and the reference value is .90 
(Bentler \& Bonett, 1980; Bentler, 1990). Finally, the parsimony adjustment index used was the root mean square error of approximation (RMSEA) of the RMR. Similarly, smaller its value, better the fit, the reference value being .05 (Steiger \& Lind, 1980).

\section{Internal consistency}

Table 1 describes the Cronbach's alpha of the SWLS scale (Diener et al., 1985) was $a=.777$ and the percentage of total explained variance $53.62 \%$. In this sense, items of homogeneity were acceptable, just with the first random half, with a minimum value of .499 (item 5) and a maximum value of .654 (item 3). Likewise, the factor loadings were: item $1=$ .735 , item $2=.664$, item $3=.821$, item $4=.757$ and item 5 $=673$.

Table 1. Mean, standard deviation, item homogeneity, kurtosis, skewness and exploratory factor loadings for the five items of the Satisfaction with Life Scale (SWLS).

\begin{tabular}{|c|c|c|c|c|c|c|}
\hline Item wording & $M$ & $S D$ & Item homogeneity & Kurtosis & Skewness & F1 \\
\hline In most way my life is closed to my ideal & 5.14 & .991 & .554 & 1.71 & -.638 & .735 \\
\hline The conditions of my life are excellent & 4.79 & 1.21 & .494 & .761 & -.560 & .664 \\
\hline I am satisfied with my life & 5.32 & 1.36 & .654 & 2.15 & -1.28 & .821 \\
\hline So far I have gotten the important things I want in life & 5.56 & 1.08 & .584 & 3.66 & -1.38 & .757 \\
\hline If I could my live over. I would change almost nothing & 4.90 & 1.31 & .499 & .074 & -.363 & .673 \\
\hline
\end{tabular}

Standard kurtosis error $=.768$; standard skewness error.350; SD= Standard deviation; F1: exploratory factor loadings for the first random half of the sample

After the Exploratory Factor Analysis, a CFA was conducted on the second random half in order to confirm the factor structure and the fit of the model. In this sense, the model had an acceptable fit; the goodness-of-fit indices global scale was: $x^{2}=12.02, p=.017(d f=4)$, Goodness of Fit Index $=.98$, Adjusted Goodness of Fit index $=.93$, Comparative Fit Index $=.97$, Normed Fit Index $=.96$, Incremental Fit Index $=97$, Root Mean Square Residual $=.05$ and Root Mean Square Error of Approximation $=.08$.

\section{Validity}

As can be seen in Table 2 the concurrent validity the Satisfaction with the Life was significantly correlated with loneliness $(r=-.193, p<.001)$ and depression $(r=-.261, p<$ $.001)$.

Table 2. Correlations of the Satisfaction with the Life (SWLS) with measures of UCLA-Loneliness and Geriatric Depression Scale (GDS).

\begin{tabular}{lcc}
\multicolumn{3}{l}{ measures of UCLA-Loneliness and Geriatric Depression Scale (GDS). } \\
\hline SWLS & 1 & 2 \\
UCLA loneliness & $-.193^{* *}$ & \\
GDS Depression & $-.261^{* *}$ & $.418^{* *}$ \\
\hline$* * P<.01 ;$ & &
\end{tabular}

\section{Discussion}

The validation of the SWLS scale to our sample of Portuguese elderly people has shown appropriate psychometric properties. With regard to the goodness of fit index, it was shown that the model with the best fit was the second model $\left(\mathrm{M}^{2}\right)$. These findings are in line from previous studies on different samples: 442 American students; 697 Spanish adolescents; 1700 healthy Dutch young adults; 2180 Brazilians; 487 Israeli adults (Anaby et al., 2010; Atienza et al., 2000; Glaesmer at al., 2011; Hultell \& Gustavsson, 2008; Neto, 1993) which support the unidimensional factor solution. The single factor of the five items of the SWLS had a total variance of $52.58 \%$. The reliability of the SWLS was .769, an acceptable reliability for the scale. This is supported by the parameter estimates of the Confirmatory Factor Analysis and is in accordance with previous findings regarding the scale's reliability (Abdallah, 1998; Bai et al., 2011; Bowlby, 1982).

With regard to validity, the correlation between life satisfaction and loneliness was negative and statistically significant (studied in this research using the UCLA instrument) and there was also a negative and statistically significant correlation between life satisfaction and the presence of symptoms of depression (analysed using GDS). This means that older people who are satisfied with their lives feel less lonely and display fewer symptoms of depression.

Other validation studies with different populations have shown that the characteristics of the sample or the participant's cultural values do not influence the perception of their life satisfaction as measured by the scale SWLS (Aishvarya et al., 2014). However, we must take into account other studies which have demonstrated the influence of contextual factors (health and the structure of the home) and cultural expectations in understanding aspects such as loneliness, a construct related to life satisfaction, in the case of the elderly (Del Barrio et al., 2010).

Although the findings of this research are supported by those from other studies, limitations have been identified. Firstly, the sample was selected through non-probability sampling, which can introduce bias into the findings. Secondly, the sample was selected from an educational programme for older people offered by several Portuguese universities, a fact which may influence the results by providing an excessively homogenous sample. Further research into subjects who are aging successfully is of particular interest given the growing interest in this profile; active aging is increasingly valued as a lifestyle related to prevention ailment 
and the improvement in the quality of life of elderly people. Finally, the concurrent validity of this study has only been checked using two scales (UCLA and GDS); however, other statistical procedures should have been included to check other types of validity such as predictive or convergence validity.

In conclusion, from the findings we can say that SWLS can be used with confidence in future research among retirees elderly people in order to measure their life satisfaction and also its relationship with other variables which affect the level of subjective well-being during this period. However, it would be necessary to complete the findings of this study, obtained through self-administered measurement, with other evaluation processes such as personal interviews or focus groups in order to measure subjective perception using both qualitative and quantitative methodologies.

\section{References}

Abdallah, T. (1998). The Satisfaction with Life Scale (SWLS): Psychometric properties in an Arabic-speaking sample. International Journal of Adolescence and Youth, 7, 113-119.

Aishvarya, S., Maniam, T., Karuthan, C., Sidi, H., Ruzyanei, N., \& Oei, T. P. S. (2014). Psychometric properties and validation of the Satisfaction with Life Scale in psychiatric and medical outpatients in Malaysia. Comprehensive Psychiatry, 55, 101-106.

Anaby, D., Jarus, T., \& Zumbo, B. (2010). Psychometric evaluation of the Hebrew language version of the Satisfaction with Life Scale. Social Indicators Research, 96, 267-274.

Apóstolo, J. L. A., Loureiro, L. M. J., Reis, I.A.C., Silva, I. A. L. L., Cardoso D. F. B., \& Sfetcu, R. (2014). Contribution to the adaptation of the Geriatric Depression Scale-15 into Portuguese. Revista de Enfermagem Referência, 4(3), 65-73.

Armitage, C. J. (2016). A brief psychological intervention to protect subjective well-being in a community sample. Quality of Life Research, 25(2), 385-391.

Atienza, F. L., Pons, D., Balaguer, I., \& García-Merita, M. (2000). Propiedades psicométricas de la Escala de Satisfacción con la Vida en adolescentes. Psicothema, 12(2), 314-319.

Bai, W., Wu, C., Zheng, R., \& Ren, X. (2011). The psychometric evaluation of the Satisfaction with Life Scale using a nationally representative sample of China. Journal of Happiness Studies, 12, 183-197.

Bentler, P. M., \& Bonett, D. G. (1980). Significance tests and goodness of fit in the analysis of covariance structures. Psychological Bulletin, 88,588 606.

Bentler, P. M. (1990). Comparative fit indices in structural models. Psychological Bulletin, 107, 238-246.

Börsch-Supan, A., \& Jürges, H. (2005). The Survey of Health, Aging and Retirement in Europe-Methodology. Institute for the Economics of Ageing. Mannheim: Mannheim Research. Available online: http://www.shareproject.org.

Bowlby, J. (1982). Attachment and Loss. Vol. 1. New York: Basic Books.

Brown, T. A. (2006). Confirmatory factor analysis for applied research. New York: The Guilford Press.

Cabañero, M. J., Richart, M., Cabrero, J., Orts, M. I., Reig, A., \& Tosal, B. (2004). Fiabilidad y validez de la Escala de Satisfacción con la Vida de Diener en una muestra de mujeres embarazadas y puérperas. Psicothema, 3(16), 448-455.

Cardona, D., Segura, A., Segura, A., \& Garzón, M. O. (2015). Contextual effects associated with depression risk variability in the elderly, Antioquia, Colombia, 2012. Biomedica, 35(1), 73-80.

Cattell, R. B. (1966). The scree test for the number of factors. Multivariate Behavioral Research, 1, 245-276.
After analysing the psychometric properties and the factor structure of SWLS when used with a group of retirees Portuguese students, we can conclude that the scale is appropriate for further use in research with this type of sample. We believe further research into life satisfaction in the elderly would be an interesting subject for future study. Given the considerable heterogeneity in this age group, we would suggest future research using this scale to analyse the life satisfaction of dependent elderly people, of people over 80 , or to compare life satisfaction of elderly people who live in rural area with those who live in urban areas. It would also be interesting to add complementary information from other reliable sources, such as close family members or carers, to the data yielded by the SWLS scale.

Chan, A., Raman, P., Ma, S., \& Malhotra, R. (2015). Loneliness and all-cause mortality in community-dwelling elderly Singaporeans. Demographic Research, 32(49), 1361-1382.

De Jong Gierveld, J., Keating, N., \& Fast, J. E. (2015). Determinants of loneliness among older adults in Canada. Canadian Journal on Aging, 34(2), 125-136.

Del Barrio, E., Castejón, P., Sancho, C. M., Tortosa, M. A., Sundström, G., \& Malmberg, B. (2010). Loneliness among the Elderly in Spain and Sweden: Context and Culture. Revista Española de Geriatría y Gerontología, Sección Ciencias Sociales y del Comportamiento, 45(4), 189-195.

Diener, E., \& Lucas, R. E. (1999). Personality and subjective well-being. In D. Kahneman, E. Diener \&, N. Schwarz (Ed.), Well-being: The Foundations of Hedonic Psychology (pp. 213-227). New York: Russell Sage Fundation.

Diener, E., Emmons, R., Larson, R., \& Griffin, S. (1985). The Satisfaction with Life Scale. Journal of Personality Assessment, 49(1), 71-75.

Expósito, F., \& Moya, M. (1993). Validación de la UCLA Loneliness Scale en una muestra española. En F. Los Certales y M. Marín (Eds.), Dimensiones psicosociales de la educación y de la comunicación (pp. 355-364). Sevilla: Eudema.

Fernández, J. J., Alcover de la Hera, C. Mª \& Crego, A. (2012). Psychosocial profiles of early retirees based on experiences during post-working life transition and adjustment to retirement. Revista de Psicología Social, 28(1), 99-112.

Fernández-Ballesteros, R. (2011). Quality of life in old age: Problematic issues. Applied Research in Quality of life, 6(1), 21-40.

Fletcher, A., Dickinson, E. J., \& Philp, I. (1992). Review: audit measures: Quality of life instruments for everyday use with elderly patients. Age and Ageing, 21, 142-150.

Garrido, S., Méndez, I., \& Abellán, J. M. (2013). Analysing the simultaneous relationship between life satisfaction and health-related quality of life. Journal of Happiness Studies, 14(6), 1813-1838.

Glaesmer, H., Grande, G., Braehler, E., \& Roth, M. (2011). The German Version of the Satisfaction with Life Scale (SWLS). Psychometric properties, validity, and population-based norms. European Journal of Psychological Assessment, 27(2), 127-132.

Gouveia, V., Milfont, T. L., Fonseca, P. N., \& Coelho, J. A. (2009). Life satisfaction in Brazil: testing the psychometric properties of the Satisfaction with Life Scale (SWLS) in five Brazilian samples. Social Indicators Research, 90, 267-277.

Horn, J. L. (1965). A Rationale and Test for the Number of Factors in Factor Analysis, Psychometrika, 30, 179-85.

Hu, L., \& Bentler, P. M. (1990). Cut-off criteria for fit indexes in covariance structure analysis: conventional criteria versus new alternatives. Structural Equation Modeling, 6, 1-55. 
Hultell, D., \& Gustavsson, J. P. (2008). A psychometric evaluation of the Satisfaction with Life Scale in a Swedish nationwide sample of university students. Personality and Individual Differences, 44(5), 1070-1079.

Jöreskog, K. G., Sörbom, D., \& Magidson, J. (1979). Advances in factor analysis and structural equation models. Cambridge, Mass.: Abt Books.

Kim, S., \& Feldman, D. C. (2000). Working in retirement: the antecedents of bridge employment and its consequences for quality of life in retirement. Academy of Management Journal, 43, 1195-1210.

Lapierre, S., Bouffard, L., \& Bastin, E. (1997). Personal goals and subjective well-being in later life. The International Journal of Aging and Human Development, 45(4), 287-303.

Lebowitz, B. D., Pearson, J. L., Schneider, L. S., Reynols, III. C. F, Alexopoulos, G. S., Bruce, M. L. et al. (1998). Actualización y tratamiento de la depresión en los ancianos. Actualización de los informes del consenso. The Journal of the American Medical Association (Spanish Edition), 7, 162-167.

Lloret-Segura, S., Ferreres-Traver, A., Hernández-Baeza, A., Tomás-Marco, I. (2014). El análisis factorial exploratorio de los ítems: una guía práctica, revisada y actualizada. Anales de Psicología, 30(3), 1151-1169.

McWhirter, B. T. (1997). Loneliness, learned resourcefulness and selfesteem in college students. Journal of Counseling and Development, 75, 460469.

Meléndez, J. C., Tomás, J. M. \& Navarro-Pardo, E. (2011). Actividades de la vida diaria y bienestar y su relación con la edad y el género en la vejez. Anales de Psicología, 27(1), 164-169.

Michalos, A. C., Hatch, P. M., Hemingway, D., Lavallee, L., Hogan, A., \& Christensen, B. (2007). Health and quality of life of older people, a replication after six years. Social Indicators Research, 84(2), 127-158.

Molina, C., Meléndez, J. C., \& Navarro-Pardo, E. (2008). Bienestar y calidad de vida en ancianos institucionalizados y no institucionalizados. Anales de Psicología, 24(2), 312-319.

Montanelli, R. G. \& Humphreys, L. G. (1976). Latent roots of random data correlation matrices with squared multiple correlations on the diagonal: A Monte Carlo study. Psychometrika, 41, 341-348.

Navarro-Pardo, E., Fernández-Muñoz, J. J., Vázquez-Martínez, A., Vázquez-Molina, J., Moret-Tatay, M. \& Civera-Mollá, C. (2015). Resilience and the Aging Process: Assessment Tools and Needs. Procedia Social and Behavioral Sciences, 191, 2008-2011.

Neto, F. (1993). The Satisfaction with Life Scale psychometric properties in an adolescent sample. Journal Youth Adolescents, 22, 125-34.

Neto, F., Barros J., \& Barros, A. (1990). Satisfação com a vida. In L. Almeida, R. Santiago, P. Silva, L. Oliveira, O. Caetano, \& J. Marques (Eds.), A acção educativa: Análise psico-social, p. 91-100. Leiria, Portugal: ESEL/APPORT.

Nunes, A. T. G. L. (2000). Serviço social e universidade de terceira idade: uma proposta de participação social e cidadania para os idosos. Textos sobre Envelhecimento, Universidade Aberta da Tercera Idade do Estado do Rio de Janeiro (UnATI/UERJ), 3(5), 1-97.
Oliver, A., Navarro-Pardo, E., Meléndez, J., Molina, C. \& Tomás, J. (2009). Modelo de ecuaciones estructurales para predecir el bienestar y la dependencia funcional en adultos mayores de la República Dominicana. Revista Panamericana de Salud Pública, 26(3), 189-196.

Pavot, W. \& Diener, E. (1993). Review of the Satisfaction with Life Scale. Psychological Assessment, 5(2), 164-172.

Pocinho, M. T., Farate, C., Dias, C. A., Lee, T. T. \& Yesavage, J. A. (2009) Clinical and psychometric validation of the geriatric depression scale (GDS) for Portuguese elders. Clinical Gerontologist, 32(2), 223-236.

Pocinho, M., Farate, C. \& Dias, C. A. (2010). Validação Psicométrica da Escala UCLA-Loneliness para idosos portugueses. Interações, 18, 65-77.

Russell, D. (1980). The measurement of loneliness. In L. A. Peplau \& D. Perlman (Eds.), Loneliness: sourcebook of current theory, research and therapy (pp. 81-104). New York: Wiley.

Russell, D. (1996). The UCLA Loneliness Scale (version 3): Reliability, validity, and factor structure. Journal of Personality Assessment, 66, 20-40.

Russell, D., Peplau, L. A., \& Cutrona, C. E. (1980). The revised UCLA Loneliness Scale: Concurrent and discriminant validity evidence. Journal of Personality and Social Psychology, 39, 472-480.

Sancho, P., Galiana, L., Gutiérrez, M., Francisco, E. H. \& Tomás, J. M. (2014). Validating the Portuguese version of the satisfaction with life scale in an elderly sample. Social Indicators Research, 115(1), 457-466.

Shin, D. \& Johnson, D. (1978). Avowed happiness as an overall assessment of the quality of life. Social Indicators Research, 5, 475-492.

Simões, A. (1992). Ulterior validação de uma escala de satisfação com a vida (SWLS). Revista Portuguesa de Pedagogia, 26(3), 503-515.

Steiger, J. H. \& Lind, C. (1980). Statistically based tests for the number of common factors. Paper presented at the Annual Meeting of the Psychometric Society, Iowa City, IA

Tabachnick, B. G., \& Fidell, L. S. (1989). Using multivariate statistics, $2^{\mathrm{a}}$ Ed., Northridge, California: Harper Collins Publishers.

Tomás, J. M., Meléndez, J. C., \& Navarro-Pardo, E. (2008). Modelos factoriales confirmatorios de las escalas de Ryff en una muestra de personas mayores. Psicothema, 20(2), 304-310.

Von Humboldt, S., Leal, I., \& Pimenta, F. (2014). Living Well in Later Life: The Influence of Sense of Coherence, and Socio-Demographic, Lifestyle and Health-Related Factors on Older Adults' Satisfaction with Life. Applied Research in Ouality of Life, 9(3), 631-642.

Weiss, R. S. (1973). Loneliness: The experience of emotional and social isolation. Cambridge, Mass.: MIT Press.

Yesavage, J., Rose, T., Lum, O., \& Leirer, M. (1983). Development and validation of a geriatric depression screening scale: a preliminary report. Journal of Psychiatry Research, 17(1), 37-49.

Zahava, G., \& Bowling, A. (2004). Quality of life from the perspectives of older people. Ageing \& Society, 24, 675-691.

(Article received: 17-09-2016; revised: 13-03-2017; accepted: 12-05-2017) 